\title{
Contribuição ao estudo da obra de Lukács sobre os problemas da ideologia e estranhamento no sistema de manipulação do capitalismo nas décadas de 1950/60
}

\begin{abstract}
Resumo
Este artigo pretende apresentar alguns aspectos gerais sobre a análise de Lukács sobre os novos fenômenos do estranhamento e sua articulação com os mecanismos econômicos e ideológicos do sistema refinado de manipulação do capitalismo nas décadas de 1950 e 1960. Acreditamos que o estudo sobre a fisionomia destes novos estranhamentos podem contribuir na pesquisa sobre a decadência cultura e ideológica do capitalismo, principalmente, com o retorno do irracionalismo moderno nas manifestações espontâneas da massa trabalhadora nos países de capitalismo avançado, tais como, EUA, Inglaterra e França, assim como, nos países de capitalismo dependente na América Latina.
\end{abstract}

Palavras-chave: Ideologia. Estranhamento. Ontologia. Lukács, György, 1885-1971. Capitalismo.

\section{Diogo Prado Evangelista}

Universidade Federal dos Vales de Jequitinhonha e Mucuri - UFVJM -

Teófilo Otoni/MG - Brasil

diogoprado32@gmail.com

Patricia Laura Torriglia

Universidade Federal de Santa Catarina - UFSC - Florianópolis/SC Brasil

patrilaura@gmail.com

\section{Para citar este artigo:}

EVANGELISTA, Diogo Prado; TORRIGLIA, Patricia Laura. Contribuição ao estudo da obra de Lukács sobre os problemas da ideologia e estranhamento no sistema de manipulação do capitalismo nas décadas de 1950/60. Revista Linhas. Florianópolis, v. 21, n. 46, p. 173-203, maio/ago. 2020. 


\title{
Contribution to the study of Lukács's work on the problems of ideology and estrangement in the system of manipulation of capitalism in the 1950s / 60s
}

\begin{abstract}
This article intends to present some general aspects about Lukács' analysis of the new phenomena of strangeness and its articulation with the economic and ideological mechanisms of the refined system of manipulation of capitalism in the 1950 s and 1960s. We believe that the study on the physiognomy of these new strangers can contribute to research on the cultural and ideological decay of capitalism, mainly with the return of modern irrationalism in the spontaneous manifestations of the working mass in countries with advanced capitalism, such as the USA, England and France, as well as in countries with dependent capitalism in Latin America.
\end{abstract}

Keywords: Ideology. Estrangement. Capitalist manipulation. 


\title{
1. Aspectos gerais do sistema de manipulação refinada do capitalismo na segunda metade do século XX
}

\begin{abstract}
[...] depois da Segunda Guerra Mundial surgiu da nova situação algo inteiramente novo [...] o nosso dever de marxistas seria o de esclarecer todos os acontecimentos posteriores ao fim do primeiro grande período. Devemos analisar o fato de que a transformação do capitalismo em um sistema dominado pela mais-valia relativa cria uma situação nova, na qual o movimento operário, o movimento revolucionário, é condenado a um novo inicio [...] devemos convencer-nos de que hoje não podemos, e relação ao despertar do fator subjetivo, renovar e continuar os anos vinte, mas devemos recomeçar de um novo ponto de partida, utilizando todas as experiências que são patrimônio do movimento operário, tal como se desenvolveu até hoje, e do marxismo. Devemos dar-nos conta, com clareza, que estamos em face de um novo início [...]. (LUKÁCS, 1969, p. 59-60)
\end{abstract}

Essas afirmações de Lukács foram realizadas a partir de uma entrevista gravada com o professor alemão Leo Kofler, em 1966, enquanto resposta à questão em torno do “[...] irracionalismo espontâneo das massas na sociedade altamente industrializada [...]." (KOFLER, 2014, p. 64) O professor Leo Kofler se referia à “integração voluntária” em massa dos indivíduos ao consumo de mercadorias, propagandas de televisão, publicidade, etc., como formas de satisfação e realização humana na ordem social. Embora, Lukács não tenha uma análise de forma sistemática e completa sobre esses novos fenômenos do capitalismo, esse problema aparece em diversos ensaios, conferências, entrevistas e, principalmente, no último capítulo do segundo tomo da obra Para Uma Ontologia do Ser Social, intitulado O Estranhamento.

Para Lukács, uma nova etapa histórica do capitalismo se desenvolve a partir da década de 1950, cuja base econômica reside na extensão, aprofundamento e predominância dos métodos de exploração do mais-valor relativo nas três esferas particulares que constituem a unidade do capital: produção, circulação e consumo. Tratase da generalização do processo de subsunção real do trabalho ao capital para a totalidade da vida social; o que significa uma nova base material de desenvolvimento tecnológico-científico para a produção capitalista de mercadorias, potencializando as forças produtivas do gênero humano em si. "[...] a mais-valia absoluta não morreu, simplesmente não desempenha mais o papel dominante; aquele papel que 
desempenhava quando Marx escrevia os Manuscritos Econômicos e Filosóficos." (LUKÁCS, 1969, p. 53).

Essa conquista material da generidade humana em si torna-se uma nova base objetiva para liberação do tempo aos trabalhadores e uma nova elasticidade para a melhoria das condições de vida dos mesmos. Importante esclarecer, Lukács considera esse processo como resultado da luta de classes, explicitamente, na diminuição da jornada de trabalho para oito horas e no aumento do salário real dos trabalhadores. No entanto, essa equação tem como base objetiva e determinante as condições reais construídas a partir do desenvolvimento das forças produtivas do gênero humano em si no interior da acumulação capitalista.

Os trabalhadores dos países de capitalismo avançado conquistaram, no período pós-II Guerra Mundial, a cidadania burguesa no interior do Estado moderno, assim como, o acesso ampliado às mercadorias. No entanto, esse movimento histórico se efetivou sob o domínio e horizonte de um sistema refinado de manipulação do capitalismo: “[...] aquela manipulação que vai da compra do cigarro às eleições presidenciais [...]." (Lukács, 1969, p. 53).

Lukács articula três aspectos desse novo desenvolvimento do capitalismo na segunda metade do século XX:1) aperfeiçoamento e extensão do processo de descoberta e aplicação tecnológico-científica nas bases produtivas da grande indústria capitalista, que intensifica o grau de exploração dos trabalhadores; 2) a abertura de um campo de possibilidades para a melhoria da qualidade de vida destes últimos, a partir do acesso a essas novas mercadorias, oriundas da extensão desta subsunção real do trabalho ao capital, tais como, eletrodomésticos, automóveis, etc.; 3) e, por último, a absorção capitalista do setor de serviços a essa nova dinâmica proporcionada pela revolução tecnológica nos meios de comunicação e nos meios de transporte; além disso, o resultado desta é a absorção capitalista do tempo "livre" dos trabalhadores sob a forma e condição de lazer, entretenimento e turismo.

No interior dos três aspectos mencionados, Lukács identifica uma nova característica no processo de compra e venda das mercadorias, no setor de serviços e na esfera do consumo individual. Em seus termos: 
[...] o interesse diretamente econômico do capitalismo nos âmbitos por ele dominados do consumo e dos serviços parece restringir-se, no plano imediato, a aumentar as vendas e, desse modo, o lucro. Contudo, para impor eficazmente esse objetivo torna-se necessário pôr em marcha um aparato que não se contenta mais só com a exaltação objetiva das mercadorias, mas exerce sobre o consumidor uma pressão moral cada vez maior. (LUKÁCS, 2013, p. 778)

Essa "pressão moral" sobre o consumidor (inclusive aos trabalhadores) atribui alguns predicados ao valor de uso das mercadorias que ultrapassam os aspectos meramente objetivos de tais produtos; o que coloca como central para a compra e consumo dessas mercadorias o aspecto subjetivo, vinculado, principalmente, a uma “imagem” de homens, mulheres, crianças, família, raça, etnia, etc. A mercadoria sob essa nova forma de existência do capital (metamorfose) manipula os consumidores para a fixação de sua realização individual nessa forma particular de sociedade. Em outras palavras, os indivíduos a partir do consumo de determinadas mercadorias aspiram a conquistar e conservar essas "imagens" como meio de formar uma personalidade que encontra a sua satisfação dentro da ordem social.

Nessa absorção capitalista do consumo e do setor de serviços, a "pressão moral" se estende para as "atividades espirituais" da reprodução do ser social, tais como, as manifestações artísticas, as ciências, a filosofia, a religião, a política, o Estado, a moral, etc. Marx (2004) identificou, nos Manuscritos Econômico-Filosóficos de 1844, a tendência de subsunção das "atividades espirituais" ao "movimento" da propriedade privada: “produção e consumo", considerando, inclusive essas atividades espirituais como "[...] formas particulares da produção [...]” e, por isso, “[...] caem sob a sua lei geral.”; ou seja, para existir e se efetivar como valor de uso as mercadorias precisam, antes de tudo, se realizar como valor de troca.

Nesta autonomia do valor que se valoriza, o sentido unilateral do ter subordina os sentidos omnilaterais do ser social. Por isso, o ser social como indivíduo somente se efetiva e se afirma na apropriação privada dos produtos sociais. Esse momento expressa um dos fenômenos do estranhamento da sociedade burguesa: a valorização crescente do mundo das coisas em proporção direta à desvalorização do mundo dos homens. O que há de novo nesta "pressão moral" aos consumidores de mercadorias? De acordo com 
Lukács, o "novo" nesse fenômeno reside no aprofundamento do "sentido do ter" na formação de "imagens" como horizonte limitado de realização dos indivíduos e expresso nestas atividades espirituais que refletem esse movimento da sociedade burguesa. Dessa maneira, as atividades espirituais, ao se transformarem em mercadorias, podem tornar-se a manifestação da forma de existência do capital, e por isso, nesta nova fase do capitalismo "universalmente manipulado", as formas ideológicas tornam-se meios complementares de prender e fixar os indivíduos às fronteiras dessa personalidade humana esvaziada de conteúdo e deslumbrante na forma.

Em outras palavras, os indivíduos em suas decisões alternativas na vida cotidiana, em sua maioria, apreendem e respondem aos conflitos e hostilidades sociais sob o horizonte do capital. Isso torna evidente a relevância da ideologia tanto na produção desses estranhamentos como nos meios de luta para a superação dos mesmos. Nos termos de Lukács:

[...] sem a mediação das formas ideológicas, nenhum estranhamento, por mais maciça que seja a determinação econômica de sua existência, jamais se desenvolverá adequadamente e, por essa razão, não pode ser superada de maneira teoricamente correta e praticamente efetiva. (Lukács, 2013, p. 749)

Ademais, Lukács reconhece essa metamorfose do capital e sua interiorização na individualidade como resultado do movimento histórico da crise econômica e ideológica do liberalismo nas décadas de 1920 e 1930, associado aos movimentos reacionários de oposição à democracia burguesa (fascismo) e à Revolução Russa de 1917 (imperialismo). No interior do movimento, Lukács destaca a necessidade de "novas formas de dominação" da “burguesia do Ocidente".

[...] o fenômeno dos novos estranhamentos surge em decorrência de um movimento do conjunto da sociedade. Esse movimento brotou do solo em que se desdobrou o capitalismo e ganhou expressão sociopolítica cada vez mais intensa no crescente antagonismo entre as formas de dominação capitalistas (incluindo nelas a chamada democracia burguesa) e a democracia. Em vista das análises feitas até agora, é suficiente indicarmos que as grandes crises ocorridas após a Primeira Guerra Mundial impuseram à burguesia do Ocidente novas formas de dominação, cujo ponto culminante, no sentido da práxis, consistiu em preservar formalmente todas as formas exteriores da democracia, aproveitando-as polemicamente tanto contra o fascismo como contra o 
socialismo, mas anulá-las faticamente por meio de seu novo conteúdo organizacional e ideológico, na medida em que as massas foram excluídas de toda real participação nas decisões econômicas ou politicamente importantes. (LUKÁCS, 2013, p. 778-779)

Nesse "novo sistema de manipulação", os processos anteriores de absorção e interiorização do capital na fixação de uma "personalidade particular" adquirem um aspecto político de dominação, precisamente, na articulação entre os meios publicitários das mercadorias para exercer "pressão moral" sobre os consumidores e a participação política na democracia burguesa. Em resumo, o sistema de manipulação transformou aquela "imagem" de personalidade dos indivíduos consumidores em eleitores, candidatos, partidos etc. Nesse sentido, a democracia burguesa se abre para a participação dos trabalhadores como eleitores e candidatos, assim como, aliados partidários nos interesses e atividades do Estado moderno, desde que estejam afastados do centro de decisões econômicas e políticas. Como realizar esta façanha? No esvaziamento de conteúdo dos complexos ideológicos sob a onipotência da publicidade e no domínio da "organização megacapitalista". Em outros termos, num processo de desideologização dos complexos ideológicos e aprofundamento do irracionalismo imperialista.

Antes de prosseguir na exposição sobre a vinculação entre o sistema de manipulação capitalista com os estranhamentos e os complexos ideológicos, é importante esclarecer que o esvaziamento e a limitação da capacidade de respostas dos indivíduos aos conflitos sociais não se efetivam de forma automática e absoluta. Ao contrário, essa massa diversificada de trabalhadores reage aos conflitos sociais em seu cotidiano de maneira heterogênea, desde a passividade da sensação de "tédio" até as manifestações politicamente organizadas dos movimentos sociais dos trabalhadores.

Porém, a questão inicial em torno das manifestações espontâneas do irracionalismo evidencia que essas reações dos indivíduos ao sistema de manipulação estão calibradas, em termos gerais, sob o sentido do "ter" e dessa individualidade particular "integrada voluntariamente" à sociedade burguesa.

Enfim, o fenômeno de manipulação da individualidade coloca sob novos parâmetros o problema do estranhamento no capitalismo, considerado por Lukács (2013, 
p. 778), como "[...] um estranhamento sui generis [...]." Isso porque coloca o problema do antagonismo da personalidade humana e a generidade humana em si como uma das condições de organização, luta e ofensiva da classe trabalhadora contra este "novo capitalismo universal e universalmente manipulado".

\section{Os "novos" fenômenos dos estranhamentos no sistema refinado de manipulação do capitalismo}

A análise de Lukács (2013, p. 577) sobre o fenômeno do estranhamento busca identificar o lugar específico que o fenômeno ocupa "[...] dentro da totalidade do complexo social do ser [...]". Essa orientação de Lukács torna-se relevante para dois esclarecimentos metodológicos. Primeiro, o estranhamento é considerado como um "fenômeno histórico-social" que ocupa uma diversidade de manifestação e desenvolvimento numa parte determinada da história da humanidade até aqui. Segundo, a formação do estranhamento não corresponde a uma "condição humana universal", ou seja, não há nenhuma "universalidade cósmica" desse fenômeno social.

No primeiro ponto, Lukács (2013, p. 577) esclarece que o surgimento do estranhamento corresponde a determinados "[...] picos do desenvolvimento em curso [...]" na história da humanidade, por exemplo, no surgimento da escravidão e servidão entre os homens como um grau histórico mais desenvolvido com relação ao canibalismo e seus impactos econômicos e sociais, tais como, uma diferenciação e extensão da divisão social do trabalho e a transição histórica da propriedade comunal para a propriedade privada.

No segundo ponto, Lukács se refere à concepção idealista de Hegel (1992b), em sua obra Fenomenologia do Espírito, que concebe o fenômeno do estranhamento como um movimento histórico de caráter universal da humanidade. De acordo com Lukács, essa concepção universal do estranhamento justifica e tornar-se um dos pilares para fundamentar na filosofia especulativa o "saber absoluto" enquanto pico culminante da humanidade.

$\mathrm{Na}$ filosofia especulativa de Hegel (1992b), o estranhamento corresponde ao movimento de objetivação do espírito na constituição da autoconsciência (consciência de 
si) alienada. Embora, a exposição de Hegel nas “figuras da consciência” se apresente num grau crescente de aproximação da coisa em si, até alcançar o esclarecimento da identidade sujeito-objeto, desde o início o pressuposto de todo esse movimento é a universalidade indeterminada do Espírito. No processo de determinação da universalidade do Espírito, um movimento de particularização da universalidade, se realiza o seu estranhamento como movimento de objetivação na forma da autoconsciência alienada. Em resumo, o espírito torna-se objetividade e possui uma historicidade nesse estranhamento com sua universalidade nas formas, duas formas incompletas de transição para a consolidação da sociedade burguesa: o "poder da riqueza" (trabalho, mercado e dinheiro) e a soberania do Estado moderno (monarquia absoluta). Hegel apresenta nas duas formas de estranhamento o problema da elevação da autoconsciência alienada (particularidade) a uma universalidade.

Como a particularidade dos indivíduos é dissolvida ou elevada à universalidade do poder da riqueza ou do Estado soberano? Na análise de Hegel, a universalidade no poder da riqueza, por exemplo, na forma de dinheiro, dissolve a particularidade dos indivíduos numa indiferença que não resulta numa elevação dessa particularidade da autoconsciência, posto que esse movimento se caracteriza como subordinação e dissolução da própria individualidade e não produz um ser-outro da autoconsciência em sua universalidade. Com relação à universalidade do Estado na forma do absolutismo, Hegel apresenta os limites da individualidade do monarca como encarnação e realização da soberania do Estado, pois, os interesses particulares do monarca entram em oposição com a universalidade da soberania estatal; o monarca como expressão da soberania absoluta do Estado se contrapõe como interesse e força particular aos interesses e forças particulares da vida privada que em seu conjunto e totalidade formam a soberania do Estado.

Nessas duas formas de estranhamento do Espírito, a autoconsciência alienada se move e autoproduz numa objetividade diferenciada e histórica que aponta, porém, não realiza o retorno à universalidade do Espírito. Antes de avançar, esclarecemos que esses dois momentos foram destacados da heterogênea exposição de Hegel sobre o estranhamento do Espírito e, não ocupam um lugar central e destacado na obra Fenomenologia do Espírito. Trouxemos estes dois exemplos por duas razões: $1^{\circ}$ ) o jovem 
Marx (2004) destaca estes dois exemplos em sua breve análise para demonstrar os limites e inversão ontológica na filosofia especulativa hegeliana sobre o estranhamento; $2^{\circ}$ ) sublinhar a relevância desse movimento do estranhamento do Espírito e a autoconsciência alienada para as questões da universalidade e particularidade como problemas históricos da formação da sociedade burguesa.

A partir desas considerações gerais acerca do estranhamento do Espírito, pode-se chegar à seguinte conclusão: o ser humano, enquanto ser objetivo, corresponde ao movimento do estranhamento do Espírito porque realiza a perda de sua universalidade indeterminada ao se determinar na negação dessa universalidade anterior e se constituir como uma particularidade. A história da humanidade aparece na filosofia hegeliana como um ciclo vicioso de perda, negação e afirmação da universalidade num grau crescente de complexidade e superioridade do Espírito. Esse processo do pensamento abstrato que põe a coisidade e a suprime para retornar a si mesmo como um ser-outro, universal enriquecida tem como pressuposto a identidade sujeito-objeto que se traduz no nosso problema na seguinte maneira: o ato de pôr a coisidade pelo Espírito é o movimento do estranhamento, na medida em que a própria coisidade é uma forma determinada do Espírito. A forma do Espírito em sua autoconsciência como objetividade é a forma de ser do estranhamento do Espírito como negação deste e afirmação em sua particularidade, ou seja, a autoconsciência alienada como objetividade. A supressão dessa forma de ser como resultado do estranhamento do Espírito, a autoconsciência alienada, se efetiva na supressão da objetividade na reabsorção desta alienação no sujeito numa nova universalidade.

Para Hegel, o lugar do estranhamento reside na contradição entre sujeito e objeto, precisamente, quando este último aparece como barreira e limites para a elevação deste sujeito, o seu devir, num ser-outro elevado, enriquecido pelas determinações anteriores, porém, numa universalidade. Lukács avança no problema do estranhamento quando traz à tona a crítica do jovem Marx à filosofia especulativa, precisamente, na seguinte afirmação materialista do ser social como ponto de partida da análise dos fenômenos do estranhamento: “Um ser não-objetivo é um não-ser.” (MARX, 2004, p. 127). O problema do estranhamento se modifica, ao considerar o ser social como um ser objetivo e a essência deste ser social como processo de atuação da subjetividade sobre forças 
objetivas existentes tanto na corporalidade do ser social quanto na coisidade externa no mundo circundante. Nos termos de Marx (2004, p. 126-127):

Quando o homem efetivo, corpóreo, com os pés bem firmes sobre a terra, aspirando e expirando suas forças naturais, assenta suas forças essenciais objetivas e efetivas como objetos estranhos mediante sua alienação, este ato de assentar não é o sujeito; é a subjetividade de forças essenciais objetivas, cuja ação, por isso, tem também que ser objetiva. O ser objetivo atua objetivamente e não atuaria objetivamente se o objetivo não estivesse posto em sua determinação essencial. Ele cria, assenta apenas objetos, porque ele é assentado mediante esses objetos, porque é, desde origem, natureza. No ato de assentar não baixa, pois, de sua "pura atividade" a criar do objeto, mas sim seu produto objetivo apenas confirma sua atividade objetiva, sua atividade enquanto atividade de um ser natural objetivo. (MARX, 2004, p. 126-127)

Nessa concepção materialista do ser social, Lukács (2013, p. 579) delimita "[...] o lugar ontológico do estranhamento [...]." no processo de objetivação da "essência humana” em "oposição” e “diferença” com o "pensamento abstrato”. Lukács atualiza e traduz a análise do problema do estranhamento na sociedade burguesa na contradição sublinhada por Marx acerca do desenvolvimento das forças produtivas do trabalho social e a reprodução ampliada do capital. De um lado, o desenvolvimento das forças produtivas corresponde ao "incremento": das capacidades humanas ou do gênero humano em si; por outro, realiza esse movimento no sacrifício e deformação da personalidade humana dos indivíduos sociais. Dessa maneira, o estranhamento corresponde ao movimento em que as forças produtivas, o mundo social produzido pelos próprios indivíduos, se defrontam com os mesmos como forças hostis que deformam e mutilam a sua individualidade. Porém, não é o aspecto objetivo das forças produtivas que explica o estranhamento, mas o modo histórico como essas forças objetivas da produção social tornam-se polarizadas e antagônicas à individualidade social.

A concepção materialista de que o mundo objetivo existe de maneira externa e independente da consciência humana, concebe toda a forma de controle e domínio humano sobre as forças objetivas da natureza como algo relativo e que encontra fronteiras intransponíveis. A determinação objetiva, causal dos produtos do trabalho, assim como, das séries causais postas em movimento pelos pores teleológicos singulares 
dos indivíduos, não podem ser eliminados por nenhuma vontade e consciência humana. Isso significa que o produto do processo social do trabalho adquire uma existência objetiva e independente da consciência humana, assim como, o desencadeamento das séries causais determina objetivamente as condições de existência do produtor. Essa característica causal, objetiva de todo o processo e resultado da produção global do trabalho não corresponde ao estranhamento e não pode ser eliminada por nenhuma vontade, carência ou interesse humano. "[...] os pores teleológicos singulares constituem ponto de partida para as cadeias causais singulares que se concentram no processo global, recebendo nele também novas funções e determinações, e que, no entanto, jamais poderão perder seu caráter causal." (LUKÁCS, 2013, p. 580).

O estranhamento emerge quando essa forma objetiva, externa e independente aos indivíduos, se confronta como barreiras ao desenvolvimento da personalidade dos mesmos, por isso, a centralidade do antagonismo entre o desenvolvimento das capacidades da generidade humana em si e a formação da personalidade humana. Porém, o estranhamento é um fenômeno histórico-social que se coloca de maneira heterogênea no conteúdo e forma em cada época histórica e em cada modo de formação social das comunidades humanas. No capitalismo, o desenvolvimento dessas capacidades humanas se realiza a partir do desenvolvimento das forças produtivas do trabalho social como meio de valorização e realização do valor-capital. A deformação da personalidade humana nesse processo está articulada com as metamorfoses do capital e, também, com os impactos da capitalização da totalidade das atividades sociais. Isso explica porque o fenômeno histórico-social do estranhamento está articulado com o processo de gênese e formação da personalidade humana dos indivíduos sociais. Mais do que isso, a formação da personalidade humana torna-se uma comprovação empírica da determinação histórico-social do fenômeno do estranhamento e sua diversidade nos "picos de desenvolvimento" da humanidade.

Uma personalidade humana só pode surgir, desdobrar e definhar num campo de ação histórico-social e concreto e específico. Por isso não base voltar a atenção unilateralmente só para a contraditoriedade - todavia profundamente embasada - entre desenvolvimento da capacidade e desenvolvimento da personalidade. (LUKÁCS, 2013, parágrafo 17) 
O processo histórico dessa formação da personalidade humana corresponde ao paulatino processo de transformação da singularidade natural do ser humano como ser vivo numa singularidade social. Esse processo se realiza desde as formas rudimentares e originárias do metabolismo entre o ser humano e a natureza até os desdobramentos e diferenciações dos complexos extraeconômicos da reprodução do ser social. Importante destacar nos momentos de transformação dos exemplares singulares da espécie humana numa singularidade social, a polarização da reprodução do ser social em singularidade dos exemplares que tornam-se indivíduos e a totalidade da sociedade (órgãos sociais de regulação da vida humana). A reprodução do ser social não supera as bases objetivas de reprodução biológica de todo ser vivo, tais como, procriar, nascer, viver e morrer; porém, esse processo se efetiva num recuo das determinações puramente naturais do ciclo vital e biológico do ser humano e o preenchimento paulatino de mediações e órgãos sociais, tais como, educação, costumes, tradições, religião, política, filosofia, moral, Estado, etc.

Não cabe neste trabalho apresentar o paulatino processo de formação da singularidade social e a peculiaridade histórica da individualidade moderna. Porém, algumas indicações gerais das contradições presentes nesse processo de formação da personalidade humana podem revelar a sua articulação com os fenômenos do estranhamento: a) princípios gerais da singularidade social dos homens no complexo do trabalho; b) os embriões da personalidade humana nessa transição da consciência numa autoconsciência humana e suas contradições com as formas de exploração e dominação dos homens entre si; c) a peculiaridade da vida cotidiana como esfera central da formação da personalidade humana, posto o campo de possibilidades de ação singulares em seus pores teleológicos, decisões alternativas. Nesse último ponto é importante sublinhar a centralidade do problema das escolhas e decisões alternativas dos indivíduos e as circunstâncias sociais encontradas (MARX, 2011).

O campo de realização dessas decisões alternativas e sua capacidade efetiva de intervir e modificar a realidade social diferenciam os homens entre si, demonstrando, na peculiaridade do seu modo de agir sobre a realidade, a expressão de sua personalidade. Esses princípios gerais das condições objetivas de formação da personalidade humana estão presentes no fenômeno originário da economia: o trabalho. Lukács (2013) apresenta no capítulo dedicado ao Trabalho, a gênese dessas decisões alternativas e a 
efetivação humana nos dois polos: pôr teleológico e causalidade; demonstrando no próprio desenvolvimento desta atividade produtiva do gênero humano, o trabalho, a extensão diferenciadora desses dois polos da produção, tais como, no pôr teleológico, a ampliação dos momentos de investigação e seleção dos meios que correspondem à contraditória relação entre as propriedades e legalidades imanentes da coisa em si (objeto) e as projeções ideais de transformação da forma desse ente material num valor de uso.

Uma objetividade existente que se subjetiva na descoberta dessas conexões das propriedades e legalidades do objeto que podem ser modificadas e o processo de subjetividade que se objetiva em algo inexistente na forma natural encontrada. Nos princípios gerais de objetivação do trabalho, Lukács apresenta a gênese desse emaranhado de escolhas e decisões da singularidade social, e as condições para incidir e modificar a realidade objetiva. Ainda no interior da exposição de Lukács acerca do trabalho, coloca-se a questão dessa subjetividade que se objetiva, modo específico do fazer singular dos produtores que imprime, paulatinamente, uma característica singular da "mão" humana em sua atividade. Esta demarcação peculiar da singularidade dos produtores no processo de trabalho corresponde, segundo Lukács, aos momentos de alienação na objetivação do trabalho.

A alienação como transferência dessas peculiaridades subjetivas e singulares dos produtores por meio do processo de objetivação do objeto. O resultado, ou seja, o produto do trabalho humano ou trabalho objetivado pode, muitas vezes, diluir e desaparecer os traços da "mão" singular do produtor; mas, isso, não deixa de existir objetivamente como resultado dessa singularidade social. Lukács dá uma diversidade de exemplos sobre essa peculiaridade singular quando coloca que, por exemplo, no ato de caça e na divisão do trabalho correspondente, aparecem casualidades e momentos inesperados que exigem respostas dos caçadores, cujo resultado pode destacar uma coragem ou medo, fuga ou enfrentamento, etc., que demarcam, também, a singularidade social de cada caçador, inclusive se destacando fora do âmbito do ato da caça. Porém, esses princípios gerais da personalidade humana, existentes como potência no complexo do trabalho, somente se efetivam na articulação entre os complexos do ser social da esfera extraeconômica na reprodução do ser social. 
De acordo com Lukács (2013), essa singularidade social existente no processo de trabalho somente se transforma numa personalidade humana quando se explicita como ser-para-si. A matéria da natureza existe como ente em si, os objetos e seres correspondentes à forma inorgânica e orgânica da natureza existem independentemente da consciência social. No processo e resultado de trabalho, essas coisas em si tornam-se um ser-para-nós. Um garfo e uma faca existem como coisas em si, ao mesmo tempo, o valor de uso de tais objetos existe para nós como valor de uso social, em que todos os membros singulares da sociedade utilizam de uma determinada forma esses objetos. Dessa maneira, a consciência do ser social corresponde à consciência do meio natural e do intercâmbio social entre indivíduos, na forma prática e ativa da consciência, a linguagem, cuja peculiaridade consiste no acesso da singularidade das coisas em si, por meio de generalidades e aproximações particulares, tais como, os nomes das coisas, suas representações em suas sinalizações, os conceitos e as descrições do movimento e qualidades das coisas em si. Por isso, o ser-para-nós expresso na linguagem pode adquirir uma particularidade na medida em que descreve e diferencia determinados objetos, porém, não alcança a sua singularidade.

De acordo com Hegel (1992a), a transposição efetiva e completa da consciência numa consciência de si ou autoconsciência somente se coloca quando o ser-outro tornase objeto para mim, na medida em que eu mesmo estou como objeto para o ser-outro. $\mathrm{Na}$ relação senhor-escravo emerge, de maneira incompleta, essa transposição da consciência numa autoconsciência quando o escravo torna-se objeto para o senhor, porém, o senhor não se coloca como objeto do escravo. O cristianismo surge, também em termos incompletos, como um dos momentos de avanço no domínio do escravo sobre si mesmo e sua libertação da vontade e domínio consciente do senhor. Embora essas considerações gerais do nascimento da autoconsciência tenham se dado no interior de uma concepção idealista da vida humana, elas apontam para algo central desta transição histórica da consciência numa autoconsciência: o ser humano como objeto dos pores teleológicos.

De fato, os embriões da formação da personalidade humana, nesse processo de consciência para uma autoconsciência, ocorrem na contradição senhor-escravo. 0 escravo torna-se objeto de pores teleológicos do senhor com a finalidade de garantir a produção material de toda a comunidade, assim como, também, libera, nesta nova 
divisão do trabalho, o senhor para realizar outras atividades sociais que têm no centro de suas reflexões e objetivações o problema da natureza específica do ser humano. Dentre estas atividades sociais, Lukács (1966) destaca a relevância da arte, inclusive como demonstração do caráter histórico na gênese da personalidade humana. Portanto, o domínio humano de si mesmo, para si, está desde o início vinculado com as formas de relação "pessoal” de exploração e dominação entre produtores e proprietários, que foram cristalizadas nas castas, estamentos, classes sociais, inclusive demarcando uma personalidade na singularidade dos membros de cada segmento no interior dessa hierarquia social. No entanto, as condições objetivas e históricas da autoconsciência, do ser-para-si que torna possível a transformação dessa singularidade social numa personalidade humana, se efetiva numa esfera imediata do fluxo da vida humana.

A vida cotidiana corresponde ao fluxo imediato dos acontecimentos, fatos e atividades sociais do ser humano. Uma dimensão importante e decisiva enquanto síntese imediata de pores teleológicos, decisões alternativas e séries causais realizadas pelos indivíduos. Esta esfera imediata da realidade social somente se desdobrou e adquiriu autonomia a partir de um desenvolvimento da divisão social do trabalho, das forças produtivas e do intercâmbio social entre os indivíduos (MARX, 2007).

Em épocas históricas anteriores da humanidade, os órgãos de regulação social que paulatinamente recuaram os órgãos biológicos, delimitaram e cristalizaram os momentos de decisões alternativas dos indivíduos. Pensar aqui o lugar da religião, da moral, dos costumes e das tradições nas decisões, atividades e pores teleológicos dos indivíduos. A personalidade humana torna-se uma síntese dessas decisões alternativas na medida em que adquire uma fisionomia e forma objetiva enquanto predicado e característica desses indivíduos. Porém, a cristalização dos indivíduos na divisão social do trabalho fixou o comportamento, as respostas e atividades sociais dos indivíduos de acordo com a casta, estamento a que pertenciam, assim como, nos princípios religiosos, místicos-mágicos ou tradicionais das comunidades humanas correspondentes.

Essa cristalização social na divisão do trabalho e de suas formas ideológicas correlacionadas predominavam nas decisões alternativas dos indivíduos na esfera da vida cotidiana. Na medida em que as respostas dos indivíduos estão orientados sob as formas cristalizadas dos órgãos sociais de regulação da vida humana, a gênese e formação da 
personalidade humana, muitas vezes corresponde ao processo de pertencimento às castas, estamentos, classes sociais e suas formas ideológicas.

Por outro lado, Lukács demonstra o devir como uma das peculiaridades da atividade produtiva do ser social. No processo de trabalho, o produto e as necessidades sociais se constituem sempre numa resposta individual ao "novo". O aperfeiçoamento no domínio consciente da natureza, tal como, na agricultura e na domesticação de animais, possibilitou um aumento da população, o sedentarismo etc., desencadeando objetivamente novos problemas e conflitos sociais. Dessa maneira, as referências tradicionais e religiosas se modificaram ou entraram em colapso societário como complexo ideológico capaz de orientar e incidir sobre os pores teleológicos e decisões alternativas dos indivíduos. Nessa contradição entre as referências ideológicas anteriores e os novos conflitos sociais, emerge tanto o campo heterogêneo de formação da singularidade social em personalidade humana, como os fenômenos do estranhamento.

Este aspecto do devir e as novas contradições e conflitos sociais são relevantes para demarcar a peculiaridade da vida cotidiana na sociedade burguesa. Embora as comunidades humanas em suas distintas épocas históricas tenham uma particularidade no processo de formação social, existe uma característica geral de delimitação da personalidade humana no domínio dos órgãos de regulação social, deixando um espaço diminuto na vida cotidiana para pores e decisões individuais "espontâneos" e peculiares de si mesmo. Nisso se diferenciam a formação e o desenvolvimento da sociedade burguesa, em que se rompem as amarras dessa delimitação e se abre um campo heterogêneo de respostas singulares cotidianas dissociadas do domínio estamental, senhorial e religioso, por exemplo, como na feudalidade.

A vida cotidiana na sociedade burguesa se desenvolve num leque heterogêneo e amplo de decisões alternativas externas aos órgãos de regulação da vida social. Por exemplo, a relação dos indivíduos e a religião na vida cotidiana moderna não se constitui por uma cristalização estamental-senhorial ou de castas; assim como, o Estado como órgão de regulação da vida social não ocupa todos os espaços dos pores teleológicos dos indivíduos e os seus problemas cotidianos. Na superfície da sociedade, isso aparece como uma emancipação dos indivíduos daquelas amarras, grilhões etc. Porém, a emancipação 
das formas cristalizadas da personalidade humana se realizou, minimamente, a partir de dois movimentos contraditórios e equalizados pela "destruição produtiva do capital”.

De um lado, a expansão do mercado mundial e o desenvolvimento das forças produtivas do trabalho social da grande indústria emanciparam e desenvolveram as energias sociais dos indivíduos numa crescente diferenciação das objetivações ideológicas superiores, tais como, as ciências, arte etc., e numa ampliação de sua mobilidade social na vida cotidiana. Nesse mesmo movimento econômico, a cooperação e dependência material dos indivíduos entre si adquiriu uma universalidade real, isto é, o mercado mundial e as forças produtivas na grande indústria expressam o grau histórico universalizante dessas capacidades do gênero humano em si.

Por outro lado, a mobilidade social dos indivíduos na vida cotidiana se desprendeu do domínio da relação "pessoal” que se expressa no Estado, religião e estamento, para adquirir um domínio de relação "coisal” pela forma acidental que a vida aparece sob os imperativos aparentes do mercado. A liberação das energias sociais somente se efetiva na transformação simultânea dessas atividades sociais em mercadorias. A mercadoria como uma das formas de existência do capital se produz, circula e consome sob o movimento objetivo da acumulação de capital, que tem como resultado desse circuito indiferente e irracional, DD', o esvaziamento do conteúdo social dessas atividades nas exigências da valorização quantitativa do valor-capital.

A família, a religião, a política, o Estado etc., são órgãos distintos de regulação social e continuam existindo como instâncias em que os indivíduos se relacionam e reproduzem entre si. Mas, a determinação do valor-capital na forma mercadoria se impõe a esses órgãos de mediação entre os indivíduos e a totalidade da vida social. Isso se explica pela acidentalidade da existência vital dos indivíduos na sociedade burguesa como resultado histórico da dissociação dos produtores de seus meios de subsistência e meios de produção, ambos, transformados em mercadorias e vinculados à acumulação capitalista. Para existirem, física e moralmente, os indivíduos precisam adquirir dinheiro para comprar os meios de vida, como ir ao mercado, padaria, escola etc.

O mercado aparece como condição essencial para se ouvir música, ler um livro, assistir a um filme, estudar, namorar etc. Além dos impulsos, vontades e quereres dos indivíduos, é necessário que haja condições objetivas para sua realização. O mercado 
torna-se historicamente, na superfície da sociedade burguesa, a condição objetiva de toda realização. Posto que todos os produtos, relações e atividades sociais perpassam na forma de mercadoria e/ou são intermediados por ela. De condição formal para realização destas atividades sociais, a mercadoria na expressão monetária de valor torna-se a determinação do conteúdo dessas atividades quando, principalmente, a finalidade e o sentido dessas atividades estão voltados para a valorização do valor, D-M-D'.

Dessa maneira, a abertura crescente para as diversas reações, decisões alternativas dos indivíduos na vida cotidiana se dá, tendencialmente, a partir do esvaziamento de seu conteúdo e da onipotência da forma valor-capital. Isso não significa a anulação dos conteúdos heterogêneos das reações individuais, mas, uma tendência histórica da relação-capital de predominar sobre as decisões alternativas dos indivíduos na vida cotidiana.

Entretanto, essa característica subjetiva da história não se realiza de forma automática. Segundo Lukács, os pores teleológicos dos indivíduos que pretendem incidir sobre as decisões alternativas de outros indivíduos possuem um campo de casualidades distintos dos pores teleológicos voltados à transformação da natureza. A própria acidentalidade dos indivíduos na vida cotidiana que os coloca vulneráveis ao poder estranho do mercado de trabalho (desemprego e/ou emprego), pode tornar-se um elemento disparador de outras reações e decisões alternativas dos indivíduos, tais como, de negar as formas de opressão e exploração do trabalho assalariado, por exemplo, ao sair do emprego (fábrica, loja, corte de cana-de-açúcar, etc.) e vagar pelo mundo afora. As reações e os pores teleológicos dos indivíduos aos conflitos sociais podem ser heterogêneos, isolados, fragmentados ou podem adquirir uma força social com outros indivíduos. Inclusive, formas de opressão vivenciadas pelos trabalhadores podem ser reproduzidas nas condutas, nas relações sociais entre si, seja dentro do trabalho ou fora dele. É no complexo dessas reações, condutas, atividades, pores teleológicos, decisões alternativas que os indivíduos na vida cotidiana vão tecendo, formando a sua personalidade humana.

O estranhamento emerge como fenômeno histórico-social, principalmente, quando a tomada de consciência e posição dos indivíduos se colocam como barreiras aos 
próprios indivíduos, ou seja, as respostas individuais preservam e, às vezes, reproduzem os próprios princípios dos conflitos sociais que enfrentam na vida cotidiana.

Nisso reside a peculiaridade dos novos fenômenos do estranhamento no sistema refinado de manipulação capitalista na segunda metade do século XX. De acordo com Lukács (2013), o grau de exploração e dominação capitalista sobre os trabalhadores no século XIX, principalmente sob o domínio do mais-valor absoluto, realizava a identidade entre os fenômenos do estranhamento com a desumanização dos trabalhadores. Isso se modifica com a generalização e base predominante do mais-valor relativo como método de exploração dos trabalhadores associado às conquistas trabalhistas e sociais dos indivíduos. Importante ressaltar que as considerações gerais de Lukács sobre esse fenômeno não pretendem criar uma identidade mecânica entre os mecanismos de exploração do mais-valor relativo com as fases e fisionomias da luta de classes. Mas, Lukács reconhece nessa nova fase histórica do capitalismo monopolista, a inserção nas pautas de luta de classes os problemas relacionados ao desenvolvimento da personalidade humana, o que traduzimos numa atualização das pautas das diferenças étnico-raciais e de gênero, por exemplo. No conjunto desses novos fenômenos do estranhamento se questionam as características e predicados da individualidade moderna, assim como, colocam em evidência os estranhamentos no interior da própria classe trabalhadora.

Lukács (2013) realiza, por exemplo, uma breve digressão sobre as formas de opressão e violência que as mulheres sofrem na relação social com os homens. Ainda que se explicite como um dos novos fenômenos do estranhamento no século XX, essa dominação violenta dos homens sobre as mulheres está presente em séculos e épocas anteriores. Na denúncia e luta pela superação das formas de dominação e violência sobre as mulheres, se coloca a superação da relação dominante-dominado, opressor-oprimido, tal como Hegel (1992a) explicitou na relação senhor-escravo, ambos presos nessa relação social. A luta contra as formas de violência contra as mulheres exige uma nova associação entre homens e mulheres, assim como, a demolição radical da figura ou imagem masculina e feminina. Na diversidade de formas de opressão vivenciadas pelas mulheres se coloca, também, o problema da igualdade real versus a igualdade forma do direito público. 
Embora a crítica de Lukács se limite ao estágio do movimento de luta social das mulheres na década de 1960, alguns aspectos tornam-se elucidativos para as características desses novos fenômenos do estranhamento como fenômenos do estranhamento sui generis: a formação da personalidade humana que tende a superar a particularidade histórico-social cristalizada e reproduzida do status quo. Trata-se de uma luta que percorre momentos de conquistas formais da emancipação política no interior do direito e da democracia burguesa, assim como, um grau desenvolvido e elevado da mobilidade social para romper as cristalizações econômicas, sociais e culturais. "[...] tudo que é sólido se desmancha no ar [...]" (MARX; ENGELS, 1998). As mesmas determinações que colocam e fundamentam tal estranhamento podem, no interior do desenvolvimento econômico, suprimir os velhos estranhamentos e colocar novos. Nesse caso específico, as conquistas do movimento feminista cabem no calibre da igualdade formal do Estado moderno e na generalização abstrata do trabalho assalariado mas não suprime, radicalmente, a relação social de violência e as formas de dominação vivenciadas pelas mulheres.

Essas conquistas no interior da ordem social burguesa tornam-se mecanismos de identidade e satisfação parcial de determinadas personalidades humanas no quadro da cidadania e mercado. Não cabe avançar nessa problemática da relação de gênero e dos debates acerca das imagens de homens e mulheres, assim como, nas formas de associação como família, casamento, monogamia etc. O que se pretende, neste exemplo, é demonstrar as novas expressões do estranhamento no século XX.

Importante notar que as mesmas condições objetivas da manipulação refinada do capitalismo que cristalizam os indivíduos a essa reprodução da personalidade humana na "imagem" do American way of life, por exemplo, tornam-se possibilidades de sua superação. O que coloca o problema da capacidade dos indivíduos de reconhecerem, se posicionarem e enfrentarem os conflitos sociais, como central, para analisar e lutar contra os "novos" fenômenos do estranhamento. 


\section{Os complexos ideológicos e os "novos" fenômenos do estranhamento}

[...] o resultado geral a que cheguei e que, uma vez obtido, serviu-me de guia para meus estudos, pode ser formulado, resumidamente, assim: na produção social da própria existência, os homens entram em relações determinadas, necessárias, independentes de sua vontade; essas relações de produção correspondem a um grau determinado de desenvolvimento de suas forças produtivas materiais. A totalidade dessas relações de produção constitui a estrutura econômica da sociedade, a base real sobre a qual se eleva uma superestrutura jurídica e política e à qual correspondem formas sociais determinadas de consciência. O modo de produção da vida material condiciona o processo de vida social, política e intelectual. Não é a consciência dos homens que determina o seu ser; ao contrário, é o seu ser social que determina sua consciência. (MARX, 2008, p. 47)

Esse trecho conhecido do Prefácio da obra Contribuição para uma crítica da economia política, publicado em 1859, influenciou marxistas e sociólogos em geral sobre a concepção da existência de uma determinação automática entre a estrutura econômica da sociedade e as formas sociais determinadas de consciência, consideradas como superestrutura. Inclusive, numa leitura rápida do trecho, pode-se concluir que os momentos da consciência somente emergem e existem na esfera da superestrutura jurídica, política, moral, religiosa ou intelectual dos indivíduos.

Numa obra do jovem Marx, nos anos de 1845-46, escrita em conjunto com Engels, podemos identificar alguns pressupostos materiais da história do ser humano que têm a finalidade de explicitar a natureza objetiva de todo ser natural. Nesses pressupostos para o primeiro ato histórico do ser humano, a consciência aparece como resultado do intercâmbio social dos homens entre si no processo de produção material de sua existência, e como expressão e forma de refletir o mundo objetivo ao seu redor. Nos termos de Marx (2007, p. 35): “[...] a consciência é, naturalmente, antes de tudo a mera consciência do meio sensível mais imediato e consciência do vínculo limitado com outras pessoas e coisas exteriores ao indivíduo que se torna consciente; [...]." Importante esclarecer que a exposição de Marx sobre esses pressupostos e determinações primárias da existência humana não corresponde a etapas evolutivas, mas formas distintas de determinação primária. O que leva à seguinte conclusão: a consciência está presente nas 
formas mais rudimentares de vínculo dos homens entre si e nas respostas singulares do ser humano às coisas exteriores, mesmo que estas se apresentem como poder estranho, tal como, Marx e Engels continuam na exposição desta passagem na Ideologia Alemã. Embora as formas sociais de consciência brotem dessa estrutura econômica do modo de produção (histórico), num grau determinado de desenvolvimento dessas forças produtivas e da divisão social do trabalho, elas adquirem uma autonomia relativa, principalmente, quando diferenciam-se entre si como atividades sociais específicas do ser social.

Antes de tudo, a ideologia pressupõe a existência de formas sociais determinadas de consciência, principalmente, quando se autonomizam como superestrutura jurídica, política, intelectual. No entanto, essas formas sociais de consciência adquirem uma fisionomia distinta em cada época histórica da humanidade, posto que, o modo de produção dessa estrutura econômica determina e condiciona a superestrutura. Cabe, neste momento, apresentar a peculiaridade das formas sociais de consciência na sociedade burguesa; Lukács as considera como momento ideal que se desenvolve nessa estrutura econômica e adquire autonomia relativa numa superestrutura que possui uma fisionomia própria, específica.

O ponto de partida da exposição de Lukács (2013) para explicar a gênese do momento ideal está no "fenômeno originário" da esfera econômica: o trabalho humano. Lukács recupera, em diversos momentos, na obra Para uma ontologia do ser social, a conhecida passagem de Marx, na obra O Capital, sobre a peculiaridade e diferença ontológica do trabalho exclusivamente humano e a atividade da abelha, o exemplo clássico na comparação entre o pior arquiteto e a abelha. Essa passagem é destacada por Lukács com o intuito de demonstrar as duas dimensões do trabalho humano: o pôr teleológico e a causalidade.

[...] mas o que distingue, de antemão, o pior arquiteto da melhor abelha é que ele construiu o favo em sua cabeça, antes de construí-lo em cera. No fim do processo de trabalho obtém-se um resultado que já no início desde existiu na imaginação do trabalhador, e portanto idealmente. Ele não apenas efetua uma transformação da forma da matéria natural; realiza, ao mesmo tempo, na matéria natural seu objetivo, que ele sabe que determina, como lei, a espécie e o modo de sua atividade e ao qual tem de subordinar sua vontade. E essa subordinação não é um ato 
isolado. Além do esforço dos órgãos que trabalham, é exigida a vontade orientada a um fim, que se manifesta como atenção durante todo o tempo de trabalho, e isso tanto mais quanto menos esse trabalho, pelo próprio conteúdo e pela espécie e modo de sua execução, atrai o trabalhador, portanto, quanto menos ele o aproveita, como jogo de suas próprias forças físicas e espirituais. (MARX, 1996, p. 298)

De acordo com Marx (1996, p. 298), a antecipação ideal do processo de trabalho não possui uma característica contemplativa e especulativa sobre o mundo objetivo ou sobre as coisas existentes na natureza. A antecipação na cabeça ou na imaginação do produtor corresponde à peculiaridade desse pôr teleológico. Primeiro, a antecipação ideal dos homens orienta o que querem fazer e como irão fazer. Segundo, o resultado do processo de trabalho corresponde a uma forma objetiva que existia anteriormente na cabeça ou na imaginação. Terceiro, a objetivação da forma imaginária na transformação da forma da "matéria natural", esta última reflete objetivamente a finalidade humana. Quarto, as vontades e necessidades humanas que impulsionaram os homens a transformarem a "forma da matéria natural" são subordinadas a essa finalidade ideal.

Desde os anos de 1843-44, o jovem Marx (2004) demonstrou que as necessidades humanas se apresentam, em sua determinação primária, como necessidades vitais de reprodução biológica, tais como, beber, comer, morar, procriar, etc.; estas últimas demonstram que os homens dependem da natureza por serem parte dela. Isso explicita a independência das coisas existentes da natureza de qualquer vontade, consciência e finalidade humana. As águas do rio continuam a fluir sem a interferência humana. Nisso reside a causalidade espontânea das coisas ou da "matéria natural".

Porém, a natureza e sua causalidade espontânea não estão de forma adequada para a satisfação das necessidades vitais do ser humano, por isso, é necessário forjar as condições objetivas para adequar a forma da matéria da natureza às necessidades sociais, isto é, transformar a característica espontânea da causalidade numa causalidade posta conscientemente.

Antes de tudo, o trabalho é um processo entre o homem e a Natureza, um processo em que o homem, por sua própria ação, media, regula e controla seu metabolismo com a Natureza. Ele mesmo se defronta com a matéria natural como uma força natural. Ele põe em movimento as forças naturais pertencentes a sua corporalidade, braços e pernas, cabeça e mão, a fim de apropriar-se da matéria natural numa forma útil para sua 
própria vida. Ao atuar, por meio desse movimento, sobre a Natureza externa a ele e ao modificá-la, ele modifica, ao mesmo tempo, sua própria natureza. Ele desenvolve as potências nela adormecidas e sujeita o jogo de suas forças a seu próprio domínio. (MARX, 1996, p. 297)

Como podemos observar, no metabolismo humano com a natureza se defrontam dois momentos constitutivos do processo de trabalho, o pôr teleológico e a causalidade. Lukács demonstra que toda a relevância ontológica que torna o trabalho humano como distinto do metabolismo de outros seres vivos com natureza está no pôr teleológico. Porém, Lukács destaca a permanência da causalidade tanto no processo de dispêndio vital do produtor em todo processo de trabalho quanto do produto, na matéria natural transformada em produto social. A transformação da causalidade espontânea da natureza numa causalidade posta conscientemente não significa que as coisas produzidas pelo ser humano se movem e existem somente a partir do pôr teleológico; ao contrário, os produtos sociais, tais como, os meios de trabalho e os meios de subsistência permanecem existindo de forma externa, objetiva e independente da consciência e finalidade humana. $\mathrm{O}$ ato do pôr teleológico termina no produto do processo de trabalho. A partir daí, se colocam em movimento séries causais independentes daquela consciência, regulação e controle do ser humano; mesmo que essas séries causais estejam vinculadas ao processo de reprodução material do ser social.

Nessas observações e conclusões sobre a peculiaridade do momento ideal na esfera econômica, Lukács avança e supera as concepções materialistas do marxismo vulgar (stalinismo) e do idealismo subjetivo e objetivo.

A autonomização do momento ideal da esfera econômica se efetiva, potencialmente, em seu interior quando, na diferenciação da divisão social do trabalho correlacionado com o desenvolvimento das forças produtivas, o pôr teleológico se desdobra em atividades sociais específicas: o "ato de pôr" e a "investigação dos meios". De acordo com Lukács, se aprofunda e desenvolve um campo de mediações entre o pôr teleológico e a causalidade posta, entre o momento ideal e a realização prática, objetivada no produto. O domínio humano-consciente sobre as forças da natureza e sua transformação em forças sociais resultou numa base material de liberação dessas energias sociais. Porém, esse processo histórico esteve, desde o início, associado aos 
fenômenos originários do estranhamento, isto é, à gênese histórica da escravidão e da servidão. Não há como dissociar o processo de autonomia do momento ideal com os antagonismos sociais de castas, estamentos, classes sociais, posto que essa autonomia corresponde à separação entre o trabalho intelectual e o trabalho manual (MARX; ENGELS, 2007).

Nisso residem os dois movimentos históricos que caracterizam o processo de desenvolvimento das formas sociais de consciência (momento ideal): de um lado, o desdobramento e potencialização do domínio consciente do ser humano sobre a natureza; por outro, o estranhamento e a hostilidade do domínio de si mesmo.

De acordo com Lukács, essa autonomia do mundo ideal da esfera econômica se desenvolve, na medida em que o recuo das barreiras naturais possibilita a transposição crescente dos órgãos biológicos de regulação da vida humana para as mediações e órgãos sociais, tais como, a família, a moral, a religião, a política, o direito, o Estado e a ética. Mas, também, quando o próprio ser humano se torna objeto de si mesmo no reflexo das formas superiores de objetivação, tais como, o devir da generidade humana nos reflexos ideais da filosofia e a particularidade dos indivíduos (personalidade humana) na diversidade da produção e manifestação artística no cultivo do sentidos espirituais do ser humano.

$\mathrm{Na}$ sociedade burguesa, o momento ideal na esfera econômica reproduz as contradições das formações anteriores destacadas do domínio consciente da natureza e o estranhamento de si mesmo, porém, numa fisionomia histórica e específica do modo de produção capitalista. O que se traduz da seguinte maneira: a autonomia do momento ideal na esfera econômica do capitalismo se vincula ao movimento de subsunção da totalidade da vida social ao capital. Lukács apresenta alguns exemplos da particularidade do momento ideal e a realização concreta, efetiva na economia capitalista, tais como, o preço das mercadorias, a polarização do ato de compra e venda no mercado; o circuito geral do dinheiro, DMD' e as diversas rubricas das metamorfoses do capital: a transformação do mais-valor em lucro, juros, etc.

A mercadoria-dinheiro como meio de circulação das mercadorias emerge como resultado e desdobramento das antinomias da forma simples de valor, porém, em um grau elevado e articulado com novas contradições e determinações econômicas. De 
acordo com Marx (1996), na forma simples de valor se coloca a antinomia entre a forma equivalente e relativa que expressa a antinomia da subordinação do valor de uso ao processo de troca de produtos. Na troca direta e simples de produtos, essas antinomias se dissolvem e somente se explicita como questão objetiva com o desdobramento do circuito de trocas dos produtos correspondentes ao excedente econômico de cada comunidade. Como resposta a essas antinomias da forma simples do valor, este último adquire uma autonomia quando o valor de uso do produto torna-se expressão ideal para realização da troca, isto é, quando o circuito da troca de produtos se transforma numa circulação simples de mercadorias. Importante observar que o processo de autonomização do valor vinculado, primeiramente, com o processo de autonomia do momento ideal da esfera econômica, está associada à subsunção do valor de uso dos produtos às condições para realização da troca de mercadorias.

Para a realização efetiva da circulação de mercadorias, o momento ideal aparece com autonomia relativa quando as mercadorias se apresentam no mercado na forma de preço, ou seja, na forma ideal de expressão monetária do valor. Porém, essa expressão somente se efetiva, concretamente, quando se realiza a compra e venda de mercadorias. No ato de compra e venda das mercadorias se polarizam dois pores teleológicos distintos: o pôr teleológico de vender, MD e o pôr teleológico de comprar, DM. O momento ideal aparece polarizado e oposto em suas finalidades, porém, somente se realiza quando se converte em seu oposto, simultaneamente, MDDM. A autonomia do momento ideal do valor se personifica em compradores e vendedores. Essa personificação econômica corresponde à subsunção das necessidades, vontades e consciência dos indivíduos aos interesses e pores teleológicos personificados do valor.

Tal processo se coloca evidente quando a mercadoria-dinheiro expressa um novo grau de autonomização do valor no circuito do dinheiro, ou seja, na forma geral de circulação do dinheiro, DMD'. A subordinação do valor de uso à realização da troca, e esta última como expressão da antinomia da forma simples do valor, se concretiza quando o dinheiro deixa de ser mero meio de circulação de mercadorias e torna-se a finalidade das mesmas. O valor deixa de ser apenas a expressão do equivalente geral de realização das necessidades e vontades humanas e torna-se a condição substancial e a finalidade última deste metabolismo social dos homens entre si. Porém, o dinheiro como expressão 
monetária do valor somente objetiva seu poder social entre os indivíduos quando pode comprar, se apropriar da totalidade de atividades, produtos e relações sociais. E, este poder social somente se efetiva na medida em que deixa de ser dinheiro, se converte em seu oposto: em valor de uso. Neste sentido, a polarização do dinheiro como ponto de partida e chegada do circuito é uma polarização abstrata, ideal e irracional. A autonomia do valor no sentido de valorização de si mesmo precisa encontrar nessa reconversão em valor uso, um movimento objetivo de valorização quantitativa de si mesmo: a compra da força de trabalho e o consumo de seu valor de uso, isto é, o trabalho.

Neste artigo não se pretende expor todos os processos de metamorfoses do capital e a subsunção da vida social aos seus imperativos econômicos. O que se pretende é destacar a peculiaridade do momento ideal na esfera econômica capitalista e os contornos gerais da fisionomia de sua autonomização, que permanece incidindo sobre as atividades e pores teleológicos nas formas sociais de consciência. Da mesma forma que os valores de uso dos produtos sociais da esfera econômica se subordinam e se efetivam sob as condicionalidades do valor, as formas de consciência e suas objetivações específicas somente se efetivam no interior dessa subsunção ao capital. Podemos observar esse fato histórico quando analisamos as formas de consciência que se destacam como órgãos de regulação social, como o Estado moderno em suas funções administrativas (econômicas) e ideológicas (política e jurídico). Assim como, nas esferas de regulação social da família e religião, por exemplo, que se modificaram na sociedade burguesa. Dentre as forças sociais que determinaram essas alterações nas direções e sentidos das formas sociais de consciência, destacam-se os complexos desse momento ideal que se tornam ideologia a partir da dinâmica das fases de reprodução ampliada do capital e da luta de classes.

De acordo com Lukács (2013), as formas sociais de consciência incidem nos pores teleológicos e nas decisões alternativas dos indivíduos na vida cotidiana, seja em conflitos ou problemas sociais episódicos dos indivíduos, seja na dimensão que envolve o devir da totalidade da sociedade. Essas formas sociais de consciência emergem como respostas que os indivíduos deram e dão às questões objetivas da vida cotidiana. Portanto, na esfera imediata do fluxo da vida, colocam-se as questões objetivas que se tornam ponto de partida dessas formas de consciência e a via de sua objetivação específica no retorno 
ao cotidiano. A peculiaridade dessa objetivação das formas de consciência explicita até que ponto e onde podem incidir sobre os indivíduos e responder as questões em seu cotidiano.

Traduzindo, a arte, a religião, a política, a ciência, o direito, etc., são produtos sociais que correspondem a essa dinâmica de questões colocadas pela vida cotidiana e as repostas dos indivíduos. A peculiaridade como a arte se objetiva na vida cotidiana está relacionada com a forma que incide sobre os indivíduos, assim como, a política, a religião, etc. Lukács destaca que a arte, a ciência e a filosofia, por exemplo, possuem uma influência na subjetividade do ser humano, não têm a capacidade de tornarem-se um meio de práxis social para enfrentar os problemas cotidianos, por isso, são consideradas formas de consciência “pura”. No entanto, a religião, a política e o direito são formas de consciência que podem regular a vida social, incidir diretamente no comportamento, no modo de responder e decidir na vida cotidiana, posto que estão vinculados à práxis social de modificação prática da realidade social. No entanto, essas formas de consciência somente podem se efetivar nos pores teleológicos e nas decisões alternativas dos indivíduos quando se tornam ideologia ou se constituem como complexos ideológicos no complexo da reprodução do ser social.

Nem toda manifestação artística como forma social de consciência torna-se ideologia, assim como, determinadas descobertas científicas ou filosóficas. As formas sociais de consciência tornam-se complexos ideológicos na medida em que contribuem na capacidade dos indivíduos de tomar consciência dos conflitos sociais e realizar os pores teleológicos e decisões alternativas para enfrentar tais conflitos. Não basta reconhecer os conflitos e se posicionar, os complexos ideológicos precisam se tornar um meio social dos indivíduos serem capazes de dirimir tais conflitos sociais. Não interessa a veracidade ou falsidade no conteúdo dessas concepções de mundo para se tornarem ideologia, e, sim a força social que podem exercer sobre os indivíduos em sua práxis social na vida cotidiana. Porém, o grau de veracidade do conteúdo dessas formas de consciência determina a durabilidade das resoluções dos indivíduos sobre os conflitos sociais, assim como, os seus desdobramentos para a própria formação das personalidades destes e as mudanças na totalidade da sociedade. 
Na obra de Lukács, algumas dessas práticas sociais específicas das formas de consciência estão vinculadas com os órgãos de regulação social que têm a função social de conservar o status quo ou expressam barreiras e fetiches para o desenvolvimento da personalidade humana, como a religião, o direito e o Estado. Infelizmente não teremos condições de desdobrar neste espaço as demonstrações desse processo de fetichização e estranhamento dessas formas de consciência, principalmente, como complexos ideológicos.

Nessa concepção dos complexos ideológicos, se vincula a questão da dinâmica da luta de classes e o reconhecimento dos indivíduos a determinadas expressões das formas de consciência para contribuir no enfrentamento aos conflitos sociais. No que diz respeito aos fenômenos do estranhamento, desde o "consumo de prestígio" até as eleições presidenciais, os complexos ideológicos exercem, na negação subjetiva de suas funções sociais, a realização das mesmas sob o imperativo de fixar os indivíduos nas formas particulares de existência da sociedade burguesa, numa realização individual sob as imagens e referências culturais que conservam a sociedade.

Esse esvaziamento tendencial dos complexos ideológicos articulados, inclusive, às formas de organização e luta da classe trabalhadora, propiciou desilusões e descaminhos que tornaram os indivíduos vulneráveis às formas de reprodução ideológica correspondentes à "produção destrutiva" do capital, ou seja, formas ideológicas de expressão do irracionalismo moderno. Essas tendências gerais apontadas por Lukács nas últimas páginas da obra Para uma ontologia do ser social indicam que mesmo em condições objetivas muito mais desenvolvidas para emancipação humana, o aspecto da fixação da personalidade humana inibe e diminui o cerco das condições subjetivas para a revolução social; tornando os complexos ideológicos como centrais para o avanço na investigação teórica e atualizada dos novos estranhamentos do capitalismo de manipulação refinada, ao mesmo tempo, como um novo início para a organização e prática revolucionária da classe trabalhadora. 


\section{Referências}

HEGEL, Georg. W. F. Fenomenologia do espírito. 2. ed. Petrópolis, RJ: Vozes, 1992a. Parte I.

HEGEL, Georg. W. F. Fenomenologia do espírito. 2. ed. Petrópolis, RJ: Vozes, 1992b. Parte II.

LUKÁCS, György. Estetica I: la peculiaridad de lo estético. Problemas de la mímesis. Barcelona: Ediciones Grijalbo, 1966. v. 2.

LUKÁCS, György. Conversando com Lukács. Rio de Janeiro: Paz e Terra, 1969.

KOFLER, Leo. Sociedade e indivíduo. Segunda conversa. In: KOFLER, Leo; ABENDROTH, Wolfgang; HOLZ, Hans H. Conversando com Lukács. São Paulo: Instituto Lukács, 2014. p. 53-94.

LUKÁCS, György. Para uma ontologia do ser social II. São Paulo: Boitempo Editorial, 2013. MARX, Karl. O Capital: crítica da economia política. São Paulo: Nova Cultural, 1996. Livro 1. V. 1.

MARX, Karl. Manuscritos econômico-filosóficos. São Paulo: Boitempo Editorial, 2004.

MARX, Karl. Contribuição à crítica da economia política. 2. ed.São Paulo: Expressão Popular, 2008.

MARX, Karl. 018 de brumário de Luís Bonaparte. São Paulo: Boitempo, 2011.

MARX, Karl; ENGELS, Friedrich. Manifesto comunista. São Paulo: Boitempo Editorial, 1998.

MARX, Karl; ENGELS, Friedrich. A ideologia alemã: crítica da mais recente filosofia alemã em seus representantes Feuerbach, B. Bauer e Stirner, e do socialismo alemão em seus diferentes profetas. São Paulo: Boitempo, 2007.

Universidade do Estado de Santa Catarina - UDESC Programa de Pós-Graduação em Educação - PPGE

Revista Linhas

Volume 21 - Número 46 - Ano 2020 revistalinhas@gmail.com 